\title{
DIÁLOGOS NA ESCOLA, CAIXA DE MEMÓRIAS: UMA EXPERIÊNCIA EXTENSIONISTA NO ENSINO FUNDAMENTAL II
}

\section{DIALOGUES AT SCHOOL, MEMORY BOX: AN EXTENSIONIST EXPERIENCE IN ELEMENTARY SCHOOL II}

\author{
MACHADO, Eduardo Gomes ${ }^{1}$ \\ FREITAS, Maria Valdelia Carlos Chagas de ${ }^{2}$ \\ SILVA, Stefania Maria Francolino $\mathrm{da}^{3}$
}

\begin{abstract}
RESUMO
Este relato de experiência apresenta uma ação desenvolvida pelo projeto de extensão Diálogos Urbanos. A atividade foi realizada em uma escola de ensino fundamental II, situada nas proximidades da Universidade da Integração Internacional da Lusofonia Afro-Brasileira (UNILAB), na cidade de Acarape, Ceará. Ancorada na metodologia da educação popular e inspirada em Paulo Freire, a experiência buscou, através da utilização e interpretação de imagens geradoras, instigar um diálogo acerca da história local, abordando o contexto histórico em que os alunos da escola estão inseridos, dotando de significação para os discentes um assunto que antes era pouco interessante. Desse modo, efetivou-se o envolvimento e interação dos discentes com as fontes históricas, criando uma narrativa própria a respeito dos conhecimentos adquiridos, transpondo a condição de meros expectadores para produtores do conhecimento histórico.
\end{abstract}

PalaVRas-ChaVE: Extensão; Escola; Educação Popular.

\section{ABSTRACT}

This experience report presents an action developed by the extension project "Urban Dialogues" (Diálogos Urbanos). The activity was carried out in a middle school located in the vicinity of the University of International Integration of Afro-Brazilian Lusophonia-UNILAB, in the city of Acarape, Ceará. Anchored on the methodology of popular education and inspired by Paulo Freire, through the use and interpretation of generating images, it sought to instigate a dialogue about local history. It addressed the historical context in which the school's students are inserted, turning meaningful to them a subject that was previously uninteresting. The

\footnotetext{
${ }^{1}$ Universidade da Integração Internacional da Lusofonia Afro-Brasileira (UNILAB) / Unidade Acadêmica dos Palmares. Acarape, CE, Brasil. ORCID: https://orcid.org/0000-0002-9321-6745 e-mail: eduardomachado@unilab.edu.br

2 Universidade da Integração Internacional da Lusofonia Afro-Brasileira (UNILAB) / Unidade Acadêmica dos Palmares. Acarape, CE, Brasil. ORCID: https://orcid.org/0000-0002-6855-8030 e-mail: valdelia@aluno.unilab.edu.br

${ }^{3}$ Universidade da Integração Internacional da Lusofonia Afro-Brasileira (UNILAB) / Unidade Acadêmica dos Palmares. Acarape, CE, Brasil. ORCID: https://orcid.org/0000-0002-6252-2635 e-mail: stef.francolino@gmail.com
} 
DOI: $10.12957 / \mathrm{e}-\mathrm{mosaicos} .2020 .46933$

activity thus implemented students' involvement and interaction with historical sources, creating a narrative of its own about the acquired knowledge and transposing their condition of mere spectators to producers of historical knowledge.

KeYWORDS: Extension; School; Popular Education

\section{INTRODUÇÃO}

A extensão universitária realiza atividades e processos que intencionam a interação e interlocução entre agentes internos e externos à universidade, cada um com suas diversidades de saberes codificados e/ou tácitos (FERRÃO, 2002, p. 20-22). Desse modo, potencialmente efetiva a indissociabilidade entre ensino, pesquisa e extensão, articulando dinâmicas formativas e de produção, circulação e partilha de conhecimentos acadêmicos e não acadêmicos. Viabilizando a oportunidade de nos tornarmos - os agentes acadêmicos - mediadores nas intersecções entre conhecimentos, saberes e experiências científicos, técnicos e do cotidiano, proporcionando e/ou apoiando sua incorporação, reconstrução e aplicação, por diferentes agentes.

O Grupo Diálogos Urbanos de Extensão e Pesquisas Interdisciplinares atua desde 2015 nas cidades de Redenção e Acarape, englobando ações de ensino, pesquisa e extensão, nas comunidades e escolas da região do maciço de Baturité. Em setembro de 2019, o grupo realizou uma atividade na Escola de Ensino Fundamental II, Padre Antônio Crisóstomo do Vale, localizada na cidade de Acarape, situada a aproximadamente 60 quilômetros de Fortaleza, capital do Ceará. Acarape é uma das cidades em que a Universidade da Integração Internacional da Lusofonia AfroBrasileira (UNILAB) foi implantada, uma universidade federal interiorizada e internacionalizada, que recebe estudantes africanos (de Angola, Cabo Verde, GuinéBissau, Moçambique e São Tomé e Príncipe), timorenses e brasileiros.

A atividade, Diálogos na Escola: Caixa de Memórias, em parceria com o Programa Residência Pedagógica do sub-eixo de História da Unilab, com a Secretaria de Educação do Município e com a própria Escola, abordou a história local a partir de imagens dispostas em uma caixa. $O$ uso de imagens como fonte histórica nos estudos acadêmicos têm significativa relevância, por ser capaz de fornecer informações que podem ser analisadas e identificadas, considerando-se personagens, espacialidades e processos sociais e históricos locais, ancorando uma contextualização das dinâmicas de ensino e aprendizagem, deslocando o caráter ilustrativo do uso de fontes históricas, hegemônico nos manuais didáticos de épocas passadas. Deste modo as ilustrações fontes históricas - assumem papel importante na produção do conhecimento histórico em sala de aula. Partindo dessa premissa a atividade foi desenvolvida dando ao estudante a oportunidade de desenvolver diversas habilidades tornando-se questionador das figuras expostas e tentando desenhar sua própria narrativa crítica acerca das mudanças e permanências apresentadas, considerando as ilustrações e as realidades sociais e históricas experienciadas. (CAIMI, 2008, p. 140, 141) 
DOI: $10.12957 / \mathrm{e}-\mathrm{mosaicos} .2020 .46933$

Fig. 01: Equipe extensionista, residentes e alunos participantes da atividade.

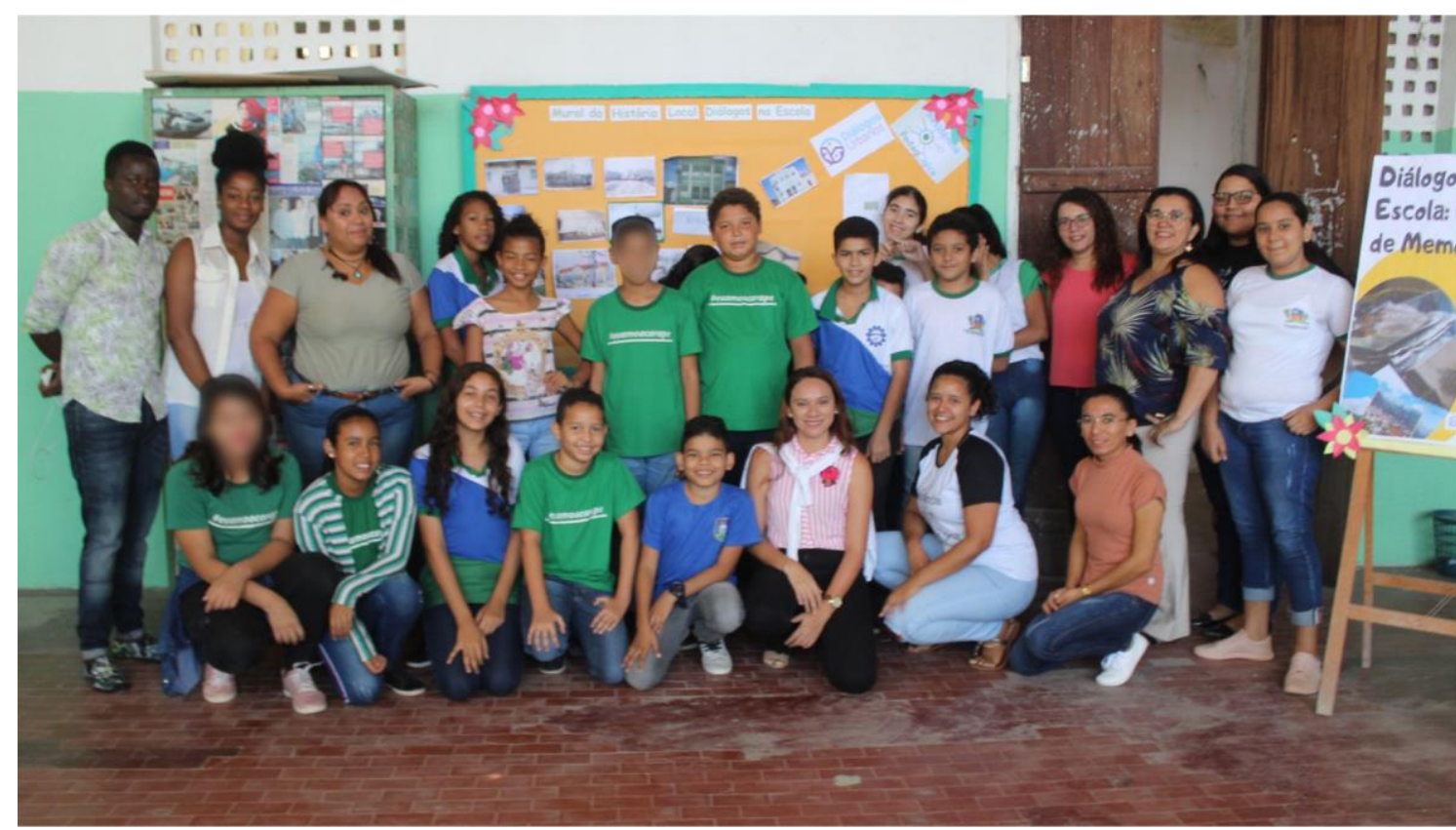

Fonte: Arquivo Projeto

A metodologia articulou três momentos distintos: (I) Elaboração de um plano de ação para realização da atividade; (II) Capacitação dos Residentes ${ }^{4}$; (III) Realização da atividade coletiva, envolvendo equipe extensionista, Residentes e alunos da escola.

Sentados em círculo os estudantes observaram atentamente a caixa de memórias colocada ao centro da roda. As imagens, selecionadas pela equipe extensionista, retratavam a história do município de Acarape e/ou de Redenção ${ }^{5}$.

Para trabalhar as imagens utilizaram-se três tipos de abordagens: significado da imagem, o que o aluno entende sobre a imagem; relação com o presente, qual a ligação da imagem com o momento atual; construção do Mural da História Local, produção do conhecimento histórico realizada pelo próprio aluno.

\footnotetext{
${ }^{4}$ Entenda-se por Residentes os bolsistas do Programa Residência Pedagógica

${ }^{5}$ Até 1987, Acarape era distrito de Redenção; por esse motivo, a história das duas cidades estão ligadas e são abordadas de maneira complementar.
} 
DOI: $10.12957 / \mathrm{e}-\mathrm{mosaicos} .2020 .46933$

Fig. 02: Alunos da escola tendo o primeiro contato com a caixa de memórias

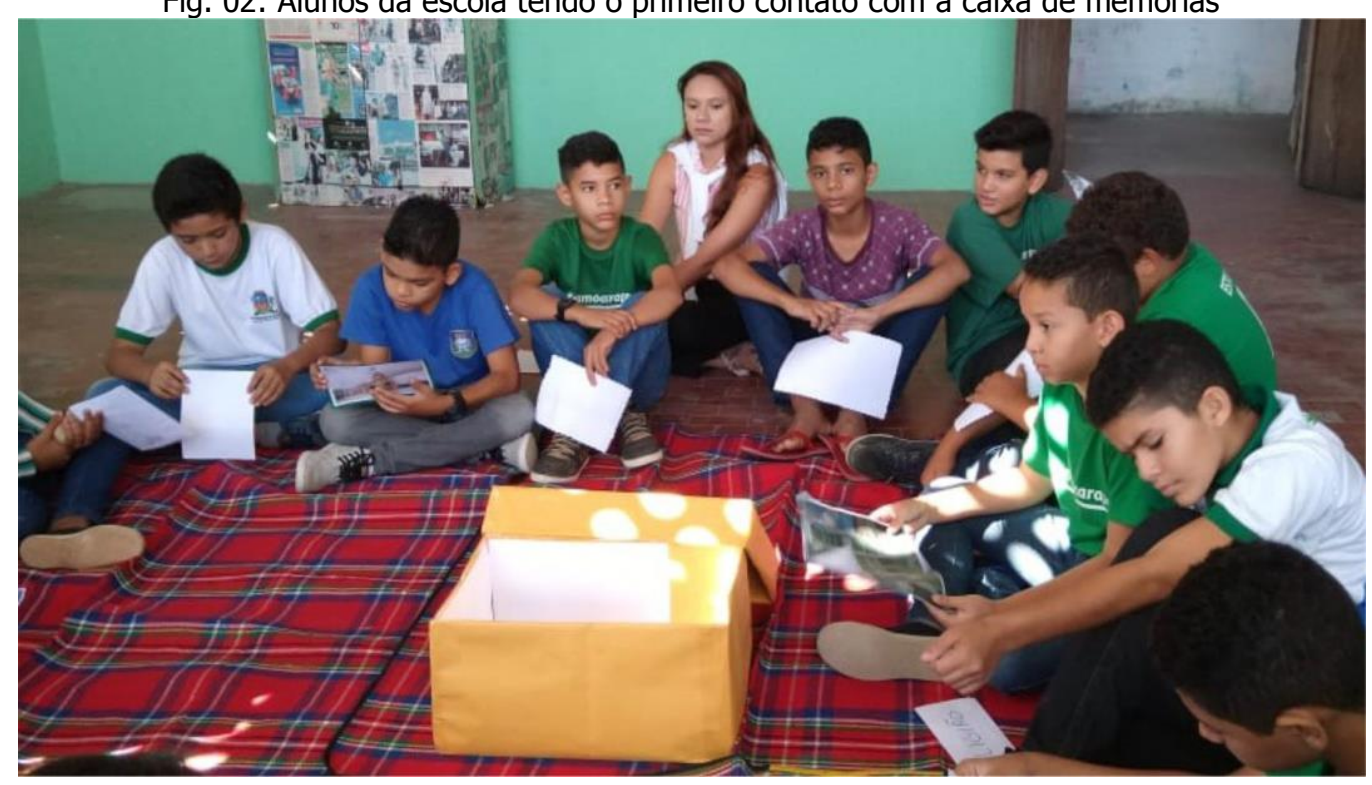

Fonte: Arquivo Projeto

A primeira abordagem fez com que os mediadores (Residentes e equipe extensionista) extraíssem dos alunos suas impressões acerca das imagens que estavam observando e manuseando. A equipe, estimulando a autonomia e aguçando a curiosidade dos alunos, buscou despertar o interesse e fazer com que eles próprios construíssem uma narrativa a respeito da imagem observada.

A segunda abordagem levou os alunos a compararem as imagens antigas com o momento atual, com os mediadores indagando sobre as mudanças/permanências ocorridas, propiciando uma reflexão acerca do tempo histórico, diferenciando o tempo ao qual o aluno pertence hoje.

Fig. 03: Residente atuando na interação do aluno com as imagens.

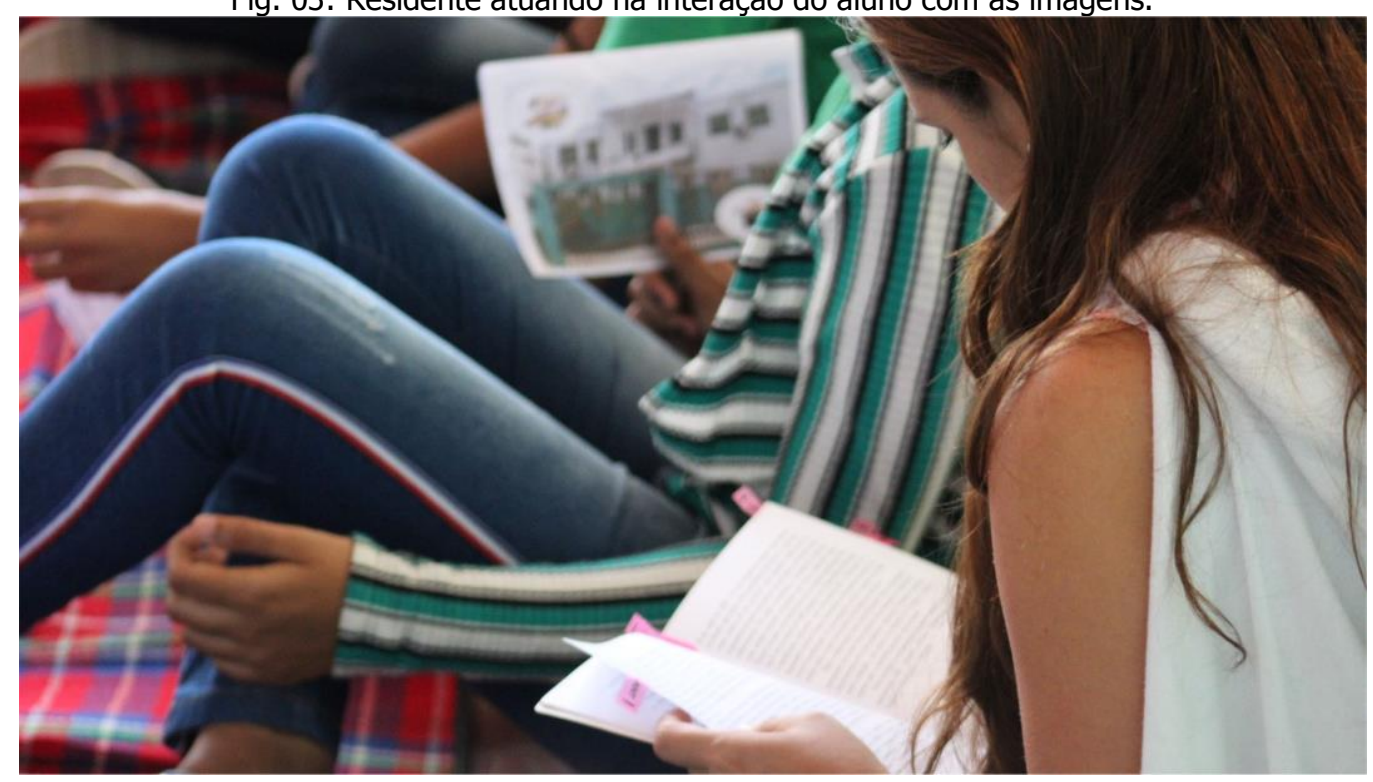

Fonte: Arquivo Projeto 
DOI: $10.12957 / \mathrm{e}-\mathrm{mosaicos} .2020 .46933$

Por fim, após a reflexão e debate sobre a história local e sobre o processo de mudanças e permanências através do tempo, os alunos realizaram um trabalho de colagem, contando a história que aprenderam e dando sentido às imagens que estavam na Caixa de Memória.

Cabe salientar que atualmente as escolas enfrentam um sério problema de dispersão na concentração dos alunos. Diversos relatos docentes acerca dessa situação foram o fio condutor para realização de uma atividade que envolvesse o aluno de modo a sair das aulas convencionais, marcadas pelo monólogo em que o professor não estabelece ligação com o cotidiano do aluno e apenas derrama seu conhecimento. $\mathrm{Na}$ maioria das vezes, sem considerar o contexto onde a escola está inserida e a heterogeneidade da turma envolvida, efetivando o que Paulo Freire chama de pedagogia bancária (FREIRE, 2011. P. 78). O Grupo Diálogos Urbanos tem como referencial metodológico o uso da educação popular nos marcos de Paulo Freire, o que foi fundamental para construir uma atividade que despertasse o interesse do aluno no processo de ensino e aprendizagem.

À luz de Paulo Freire, que desenvolveu o método das palavras geradoras, acreditando que as palavras precisam fazer/ter sentido para quem fosse aprendê-las (MACHADO, 2018, p. 94), afirma-se que utilizamos uma espécie de pedagogia da imagem geradora. Através do uso/observação de imagens que remetem a fatos históricos ocorridos na localidade, pode-se abordar o contexto histórico onde os alunos estão inseridos, dotando de importância um assunto que antes era visto com desinteresse pelos próprios estudantes.

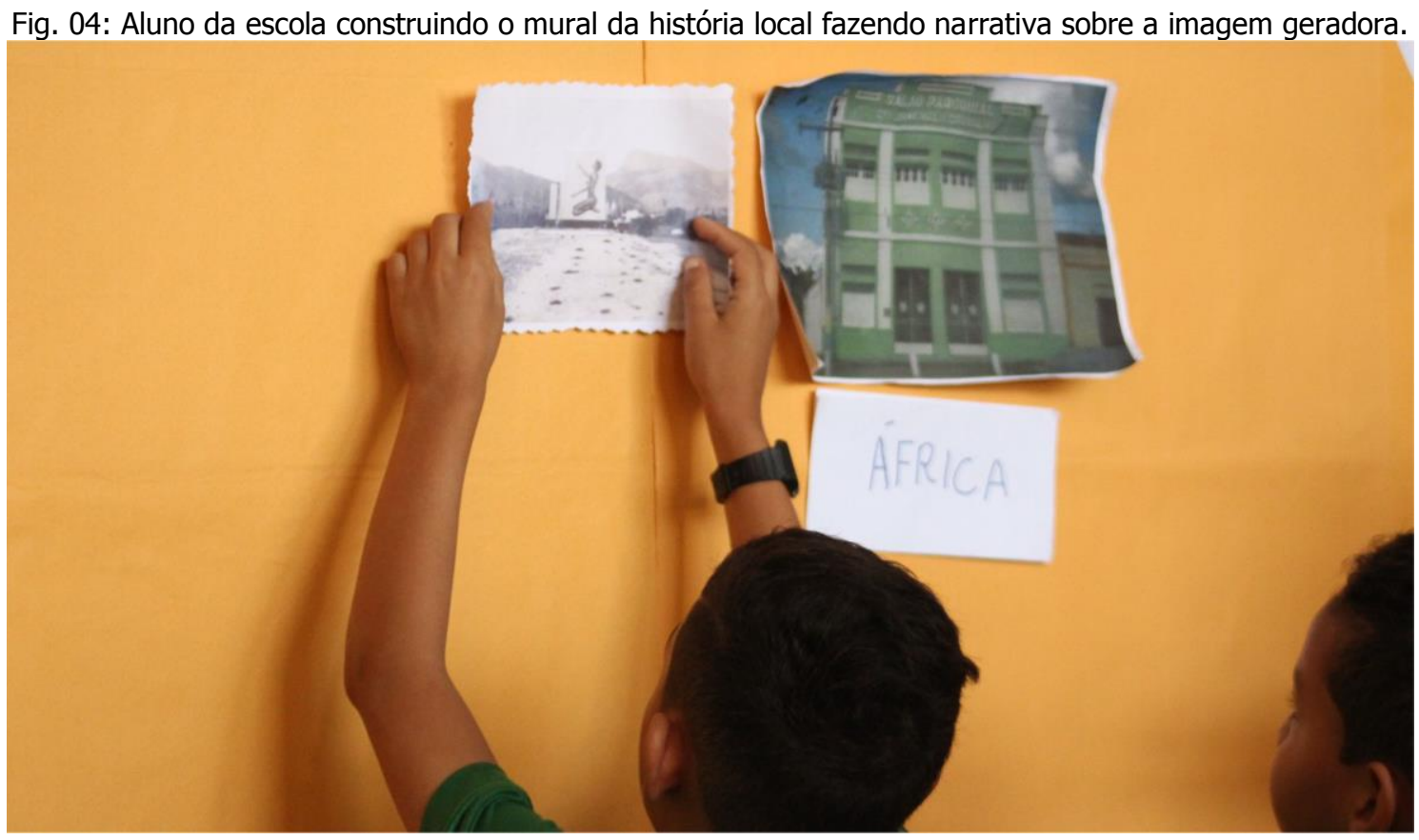

Fonte: Arquivo Projeto 
DOI: $10.12957 / \mathrm{e}-\mathrm{mosaicos} .2020 .46933$

Avalia-se que o evento atingiu de modo positivo e significativo os alunos da escola e os mediadores. Durante o desenvolvimento da atividade foi visível o interesse dos alunos, que participavam ativamente, questionando as imagens e contando histórias acerca dos lugares representados. Os mediadores estiveram sempre atentos as abordagens dos alunos, ajudando a aguçar a curiosidade pelos lugares em que eles estão imersos, para depois fazerem ligação com a história local. A percepção dos alunos de que a história faz parte do seu cotidiano foi o instante mais gratificante de toda atividade e se deu no momento da construção do Mural da História Local, onde iam escolhendo as imagens e contando um pouco da história do lugar aliada à sua história pessoal.

Fig.5: Mural construído pelos alunos enquanto faziam suas narrativas acerca da história local.

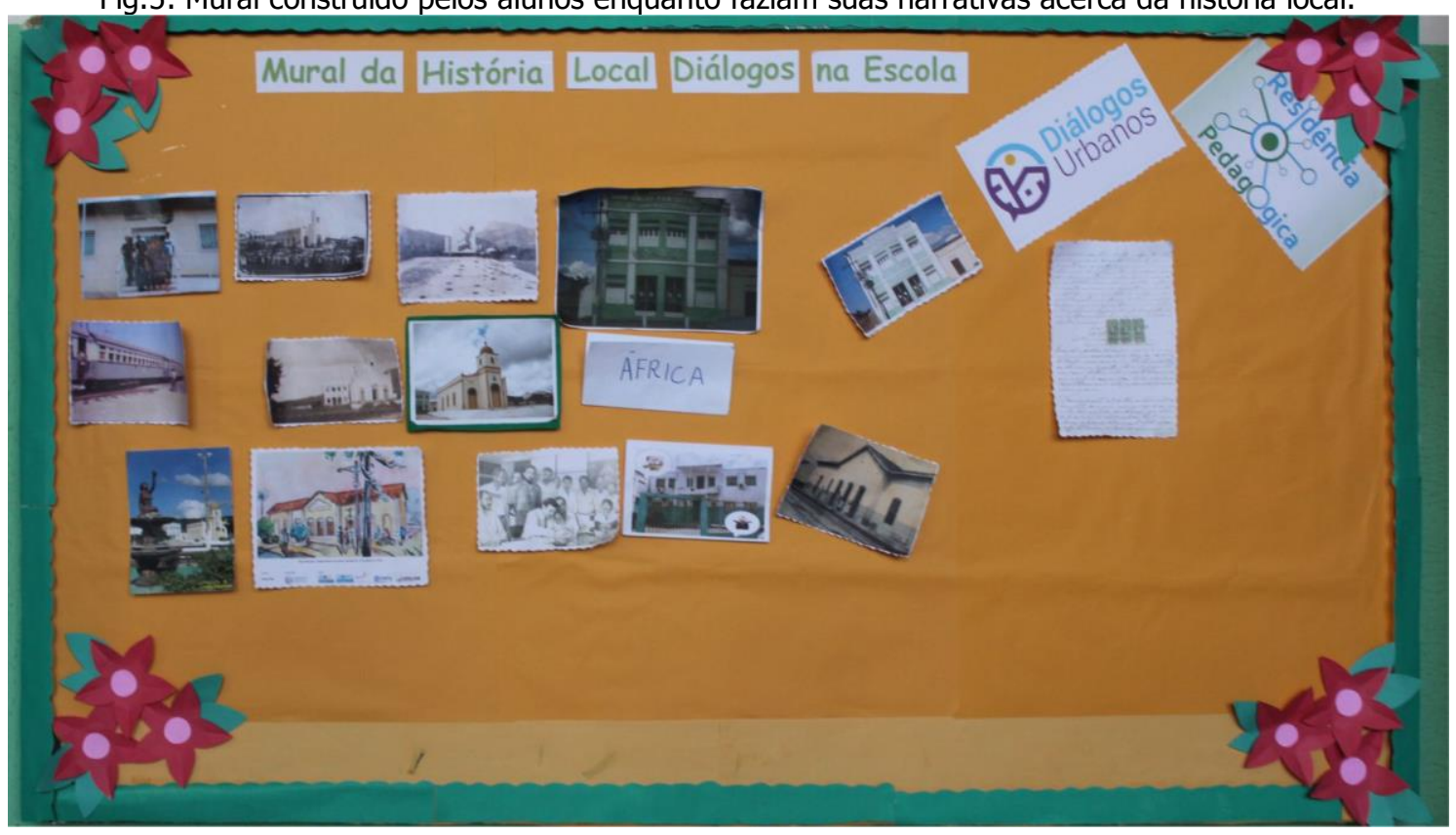

Fonte: Arquivo Projeto

A proximidade dos alunos com as fontes históricas dispostas os fez sair da condição de meros expectadores para produtores do conhecimento histórico. De todo modo, aos poucos pretende-se ir consolidando a metodologia, em outras aplicações, inclusive incorporando sugestões e críticas.

\section{NOTA DE AGRADECIMENTO}

Os autores registram e agradecem o apoio da Universidade da Integração Internacional da Lusofonia Afro-Brasileira (UNILAB), da Pró-Reitoria de Extensão, Arte e Cultura (PROEX), da Coordenação de Aperfeiçoamento de Pessoal de Nível Superior (CAPES). Também agradecem aos Residentes do Programa Residência Pedagógica em História (PRP), à Secretaria de Educação de Acarape (SME), à escola Padre Antônio Crisóstomo do Vale e aos seus gestores, aos professores, estudantes e famílias que contribuíram com a realização da atividade, assim como aos pareceristas anônimos, pelas valiosas contribuições. 
DOI: $10.12957 / \mathrm{e}-\mathrm{mosaicos} .2020 .46933$

\section{REFERÊNCIAS}

CAIME, Flávia Eloisa. Fontes históricas na sala de aula: uma possibilidade de produção de conhecimento histórico escolar? Anos 90, Porto Alegre, v. 15, n. 28, p.129-150, dez. 2008

FERRÃO, J. Inovar para desenvolver: o conceito de gestão de trajectórias territoriais de inovação. Interações, Revista Internacional de Desenvolvimento Local. Vol. 3, N. 4, p. 17-26, Mar. 2002.

FREIRE, Paulo. Pedagogia do oprimido. 50. ed. São Paulo: Paz e Terra, 2011.

MACHADO, Eduardo Gomes. Desafios da intervenção acadêmica no planejamento urbano: diálogos sociológicos com a educação popular em Paulo Freire. In: Elaine Ferreira Rezende de Oliveira; Larissa Oliveira e Gabarra; Leandro de Proença Lopes. (Org.). Construindo pontes: Paulo Freire entre saberes, projetos e continentes. 1ed.FORTALEZA: EDUECE, 2018, v. 1, p. 77-100.

Recebido em 27 de novembro de 2019 Aceito em 29 de março de 2020

A e-Mosaicos Revista Multidisciplinar de Ensino, Pesquisa, Extensão e Cultura do Instituto de Aplicação Fernando Rodrigues da Silveira (CAp-UERJ) está disponibilizada sob uma Licença Creative Commons - Atribuição-NãoComercial 4.0 Internacional.

Os direitos autorais de todos os trabalhos publicados na revista pertencem ao(s) seu(s) autor(es) e coautor(es), com o direito de primeira publicação cedido à e-Mosaicos.

Os artigos publicados são de acesso público, de uso gratuito, com atribuição de autoria obrigatória, para aplicações de finalidade educacional e não-comercial, de acordo com o modelo de licenciamento Creative Commons adotado pela revista. 